\title{
Location of Event Occurrence ICSR Terminology
}

National Cancer Institute

\section{Source}

National Cancer Institute. Location of Event Occurrence ICSR Terminology. NCI

Thesaurus. Code C54590.

Terminology used in Individual Case Safety Reports to specify information on a location where an event occurred, section F12 of FDA MedWatch Form. 